\title{
A survey of river versus lake water supplied to a drinking water treatment plant in Alabama
}

\author{
A. Nabors, P. Barron \& J. Heberling \\ Department of Engineering, Birmingham Water Works Board, USA
}

\begin{abstract}
Raw water quality, specifically total organic carbon (TOC) and chlorine demand, are of particular concern to the treatment process due to upcoming tightening regulations. To address this, the Birmingham Water Works Board developed the following study in an effort to further improve finished water quality. This year a survey was performed at Shades Mountain Filter Plant (SMFP) to monitor the influent water quality to the plant. The objective was to evaluate the difference in chlorine demand and TOC for the two primary source waters, Cahaba River and Lake Purdy. Initially sampling was performed at the following locations throughout the SMFP system: Upstream Cahaba River, Cahaba Pump Station, Lake Purdy, Bottom of Lake Purdy dam, Bridge located downstream from Lake Purdy, SMFP receiving basin, SMFP flume or rapid mix. These sites were chosen for their ability to provide information on each water source independently as well as information pertaining to their combination at SMFP. Sampling occurred during and/or after several weather events to capture all weather variations. Initial results suggested that Lake Purdy had higher TOC than the Cahaba River. Consequently, the Little Cahaba site was added approximately two miles downstream of Lake Purdy just before the junction of the two source waters. It will provide crucial information as to what the water quality of Lake Purdy is just before it is combined with the Cahaba River and sent to the plant as a blend. Evaluation of the water quality at this new site downstream from the lake is important because it will help determine if additional pre-treatment or reservoir treatment will be beneficial.
\end{abstract}

Keywords: total organic carbon, TOC, water quality, raw water comparisons. 


\section{Introduction}

With the Stage 2 Disinfectants/Disinfection By-products Rule (DBPR) [1] less than a year away, the need for drinking water treatment plants to fully assess their operations and distribution systems for efficiency in optimization is upon us. There are several ways to approach meeting the new regulations for disinfection by-products (DBPs). One of the most utilized methods is through enhanced coagulation. This process is fairly simple for most treatment plants since it generally involves very little to no physical changes in the treatment process at the plant and simply using chemical coagulation at its maximum. This can cause additional costs for chemicals at the plant but overall is a fairly affordable option when compared to others. Other options include evaluating the use of a pre-oxidant. Studies show that by merely changing the pre-oxidant used at the plant it is easy to achieve as much as 30\% reduction in DBPs [2-4] or that by simply allowing granular activated carbon filters to go biological you can improve the removal of total organic carbon (TOC) by 10 to $20 \%$ [5].

However, an option that seems to be utilized less often is the importance of the raw water quality of the source water that supplies a treatment plant. If proper care is taken to enhance the quality of the water before it reaches a treatment plant, less money will be needed to create a finished product that is able to meet all of the 2012 DBPR regulations. It is for these reasons that the Birmingham Water Works Board (BWWB) initiated this study.

\subsection{Project scope}

The scope of the project is two-fold. The first is to obtain data on TOC for the two primary source waters, Cahaba River and Lake Purdy, supplying Shades Mountain Filter Plant (SMFP). The second is to evaluate the difference in chlorine demand for the two primary source waters to SMFP. There is also valuable information in determining the relationship between TOC and resulting chlorine demands of each individually.

\subsection{Project description}

TOC and chlorine demand are of particular concern throughout the treatment process due to their direct effect on overall water quality regarding their connection to the formation of DBPs. An increase in TOC will generally result in an increase in chlorine demand which will in turn create an increase in DBP formation [6-9]. If precursors to DBP formation in the system are not maintained properly it could result in a failure to meet the Stage 2 DPBR in 2012.

\subsection{BWWB background}

The BWWB is located in Birmingham, Alabama, USA. Birmingham is located in the south eastern United States 147 miles $(237 \mathrm{~km})$ west of Atlanta and 209 miles $(336 \mathrm{~km})$ north of the Gulf of Mexico. Birmingham residents enjoy a 
humid, subtropical climate with average summer highs in the lower 90's (32-34 ${ }^{\circ} \mathrm{C}$ ) and average winter lows in the mid 30's $\left(1-3{ }^{\circ} \mathrm{C}\right)$. Rainfall is distributed evenly throughout the year with October being the historically driest month.

The BWWB owns and operates four separate surface water treatment plants spread across the Birmingham area that serve approximately 600,000 people within five different counties: Jefferson, Shelby, Blount, St. Clair, and Walker. The plants range in age and size with the oldest plant being over 100 years old and having the capability to treat the majority of the water that is distributed to the region. This plant is known as Shades Mountain Filter Plant (SMFP) and serves approximately $50 \%$ of the demand during almost all times of the year. SMFP will be the plant that this study focuses on. SMFP was originally constructed in the 1890's and has a daily max rate of 80 million gallons per day. It has two separate raw water sources, the Cahaba River and Lake Purdy.

\subsubsection{The Cahaba River}

The Cahaba River provides a habitat for more fish species per mile than any river in the U.S. and is a home to a diverse number of plants and invertebrates [10]. It touches 8 counties and is estimated at 190 miles in length, making it Alabama's longest free flowing river. There are over 100 discharge permits including six wastewater treatment plants in the Upper Cahaba region alone causing a fair amount of concern over this river as a raw water source due to its susceptibility for contamination.

\subsubsection{Lake Purdy}

Lake Purdy serves as a reservoir for drinking water supply during dry seasons. It was first dammed in 1911 at the headwaters of the Cahaba River at what is known as the Little Cahaba River tributary. The dam has a straightforward valve system with the ability to open and close certain valves at different heights throughout the dam based on the demand. It is also open to the public and used for recreational purposes such as fishing.

\section{Materials and methods}

\subsection{Sample sites}

There are a total of eight sample sites for the project located throughout the SMFP system: Upstream Cahaba River, Cahaba Pump Station, Lake Purdy, Bottom of Lake Purdy dam, Bridge located downstream from Lake Purdy, Little Cahaba, the SMFP receiving basin, and the SMFP flume. These eight sites are divided into three separate categories: Cahaba sites including Upstream Cahaba and the Cahaba Pump Station; Purdy sites including Lake Purdy, Purdy Below Dam, Purdy Bridge and Little Cahaba; and Plant sites including SMFP Raw and SMFP Flume. Each site was chosen based on its ability to provide specific information about each individual raw water source as well as depict what the final blend at the plant is. 
The site labelled Little Cahaba was added to the original list to provide additional information about the raw water coming from Lake Purdy at the last point before it is blended with the water from the Cahaba and enters the treatment plant. This is important because at the six month mark of sampling it appeared that Lake Purdy had much higher TOC than the Cahaba and the bridge located downstream from Purdy indicated that there was a possible loss in TOC
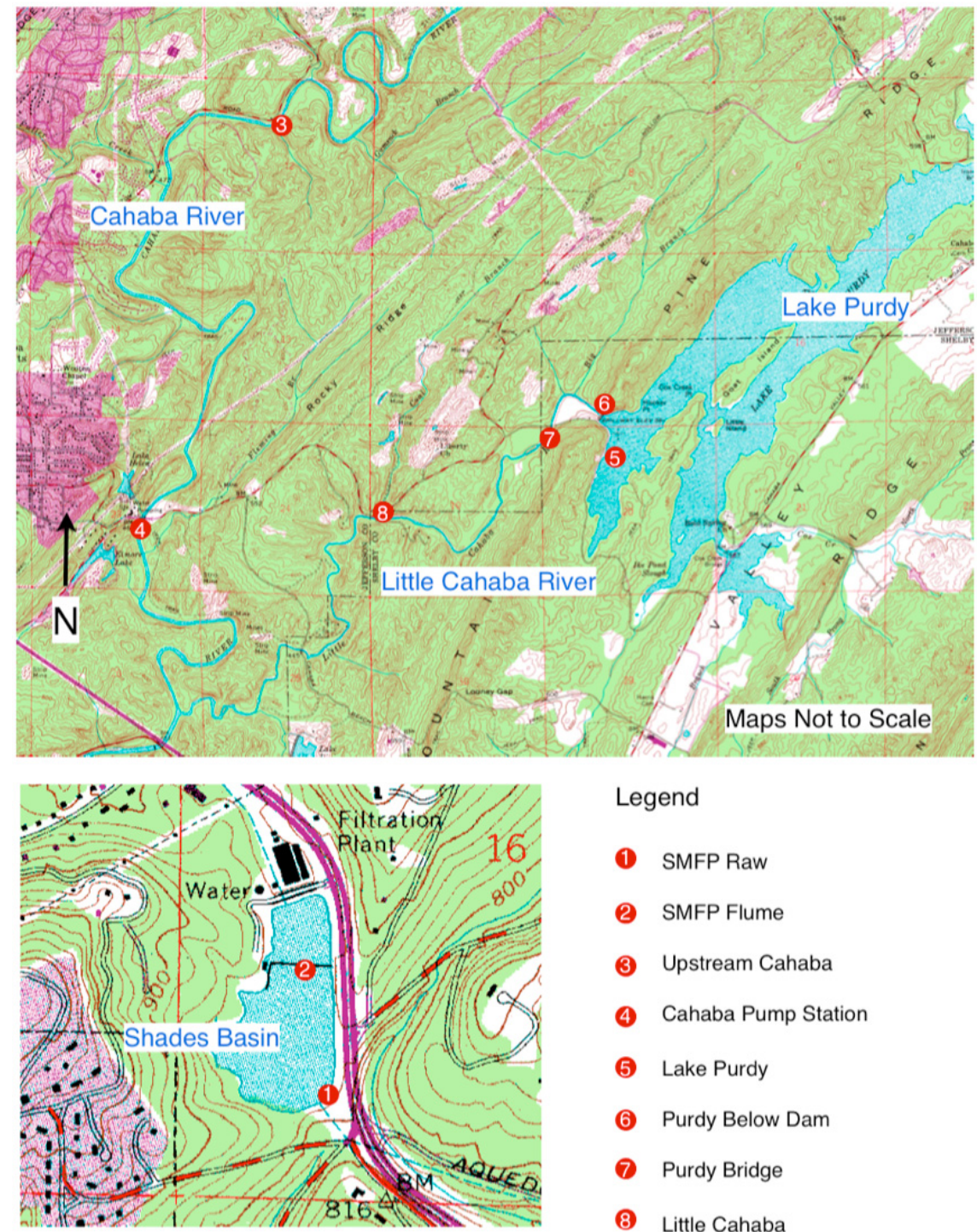

Legend

(1) SMFP Raw

(2) SMFP Flume

(3) Upstream Cahaba

(4) Cahaba Pump Station

(5) Lake Purdy

6 Purdy Below Dam

(7) Purdy Bridge

8 Little Cahaba

Figure 1: USGS topography maps of Shades Mountain Filter Plant, Cahaba River and Lake Purdy $[12,13]$. 
as the water was transported from the Lake to the plant [11]. This new location would provide data as to whether or not the TOC from the Lake remained as high or if degradation occurred during the transport.

\subsection{Sample procedures}

A one litre sample was collected from each of the sample sites to evaluate the chlorine demand, temperature, $\mathrm{pH}$, turbidity, and weather conditions. With the exception of Lake Purdy, all samples were collected from free flowing water. Proper sampling techniques were used to pull upstream from the sampler to ensure that the sample taken was not disturbed or influenced by the sampler in any way.

Samples were pulled biweekly for the first nine months and then monthly since then. Sample days are determined by weather conditions as well as the sampler's availability since the total process of collection and analysis can take up to eight hours. Weather conditions have been the primary factor influencing sample days because it is important to evaluate what role weather conditions play on the results. Weather conditions that have been included in the study are sunny, partly cloudy, cloudy and/or overcast, raining, thunderstorms or heavy rain events lasting several days, and even ice.

\subsubsection{TOC procedure}

Concurrently, two forty millilitre samples were also collected biweekly over a six month period from each of the original seven sites to evaluate TOC. After the initial several months an eighth site was added to the list and sampling occurred biweekly to monthly. Each sample was immediately preserved with phosphoric acid on site then taken to Envirolab, an EPA certified lab owned by BWWB, where analysis occurred within the two week holding time.

\subsubsection{Chlorine demand procedure}

Five hundred millilitres from each of the sample sites were spiked with sodium hypochlorite to evaluate the chlorine demand of the sample. Each sample was spiked with a "low" dose and slowly agitated with a stir bar for approximately 2 minutes to allow for proper mixing. Once a $5 \mathrm{~mL}$ portion was collected for chlorine residual analysis, the sample was then spiked with the second dose creating the "high" dose. The "low" dose was $2.4 \mathrm{mg} / \mathrm{L}$ (or ppm) and the "high" dose was $4.8 \mathrm{mg} / \mathrm{L}$ (or ppm). Each sample was then analyzed using the DPD colorimetric method to determine what the difference in chlorine demand would be between each of the sites.

\section{Results and discussion}

\subsection{TOC results}

Six month preliminary data showed a very distinct difference in TOC between each of the three categories of sample sites: Cahaba, Purdy, and Plant. This difference is illustrated in Figure 2. 


\section{Average TOC Data}

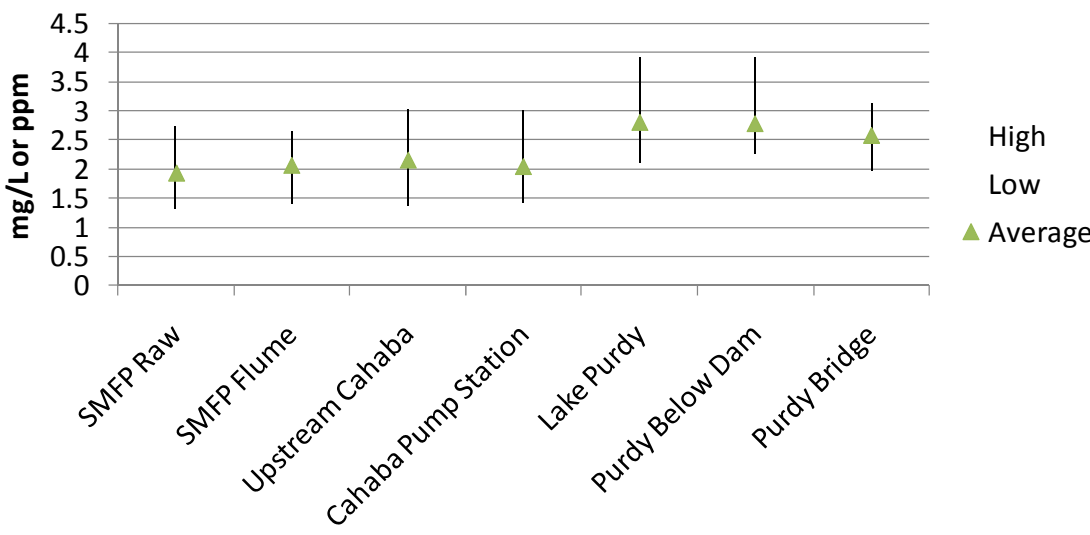

Figure 2: $\quad$ Average TOC values for preliminary data [11].

The two Cahaba sites show very similar results for their high and low points as well as their averages. The two Plant sites also show very similar results for their high and low points as well as their averages. However, a distinct difference can be seen when comparing the averages of the Purdy sites against the other two categories as well as against one another. The first noticeable difference is that all three averages in the Purdy category are significantly higher than the other two subcategories. The second noticeable difference is that the Purdy Bridge has a much lower high and low point as well as average when being compared to Lake Purdy and Purdy Below Dam which appear to share very similar data. This was the basis for the addition of the eighth sample site.

Interestingly, when data from a thirteen month period is calculated it depicts a somewhat different graph. This time the averages of all sites fall into a small range of approximately $0.48 \mathrm{mg} / \mathrm{L}$. This is illustrated in Figure 3 .

One of the first key points about this graph is that the Purdy averages changed very little between Figure 2 and Figure 3. The reason the averages are so close now is because the average TOC of the Cahaba and Plant categories had a significant increase. It is thought that this phenomenon may be due to the extremely wet year the region experienced in 2009 and the much drier year of late 2010. On December 30, 2009 Lake Purdy was at full pool and on December 30,2010 the lake was only at approximately 75\%. This shows a significant difference in rainfall between the two winter seasons. Another possibility is that it is simply a result of seasonal variation.

Secondly, the Little Cahaba site that was added to the Purdy category shows important information. There is a slight decrease in average TOC as the water leaves the lake and flows through the four Purdy samples sites. This decrease can be calculated as less that $5 \%$ from one sample site to the next showing that there is not a significant amount of degradation to the TOC during the transport. Furthermore this phenomenon is seen with the fact that the Little Cahaba site has a higher "high" point than Purdy Below Dam and Purdy Bridge. 


\section{Average TOC Data}

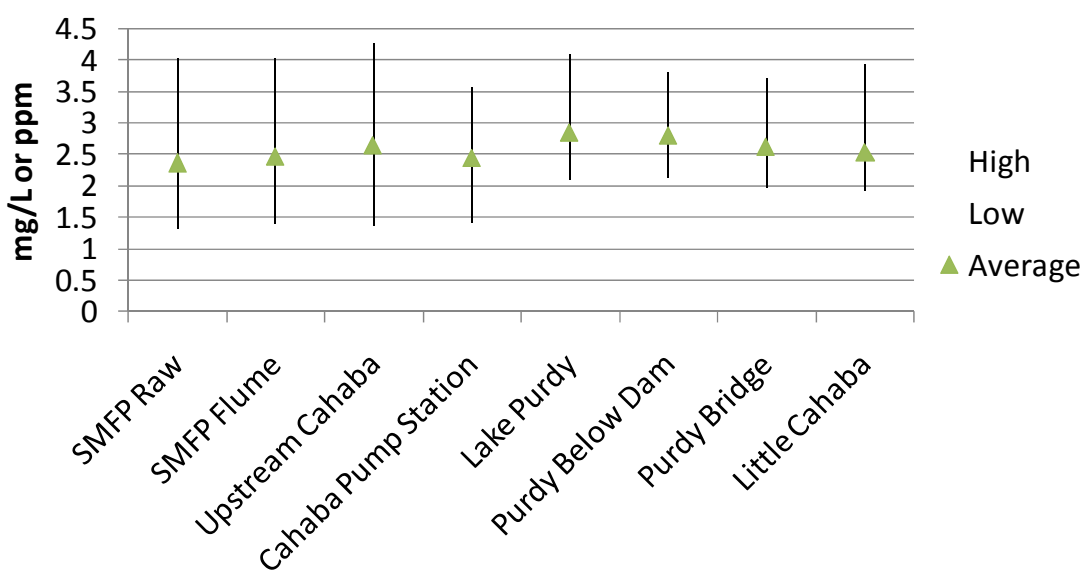

Figure 3: Average TOC data for one year.

Lastly, it is interesting that the "high" point to "low" point range for the Cahaba and Plant sites is much larger than the range for the Purdy sites. This can most likely be attributed to the fact that the River is more vulnerable to weather events such as flash flooding from large rain events. This isn't to say that Lake Purdy is not affected by weather events just possibly not at the same rate.

\subsection{Chlorine demand results}

The chlorine demand data is important because it is an indicator for DBP formation in the distribution system after the treatment process. It can also suggest chemical demand and associated costs for treatment. As expected, results from the chlorine demand portion are similar to the TOC results and are illustrated in Figure 4.

In concurrence with the TOC data, the chlorine demand for the Purdy category is significantly higher than either of the Cahaba or Plant categories. In fact, the average "low" dose demand is higher than the average "high" dose demand of all four sites within the Cahaba and Plant sites. This will play a notable role on treatment at the plant causing for the addition of more chorine or other pre-oxidants thereby causing an increase in DBPs [2-4].

\subsection{Integration of TOC and chlorine demand data}

Figure 5 illustrates the relationship between the average TOC and average "low" dose and "high" dose chlorine demand. 


\section{Average Chlorine Demand Data}

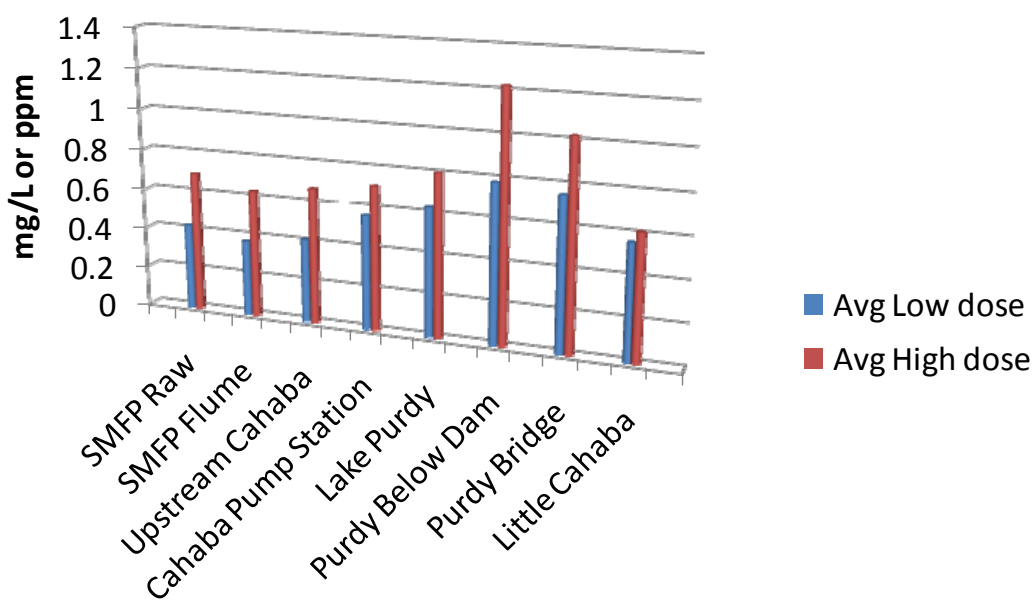

Figure 4: $\quad$ Average chlorine demand data.

\section{Integration of TOC and Chlorine Demand Data}

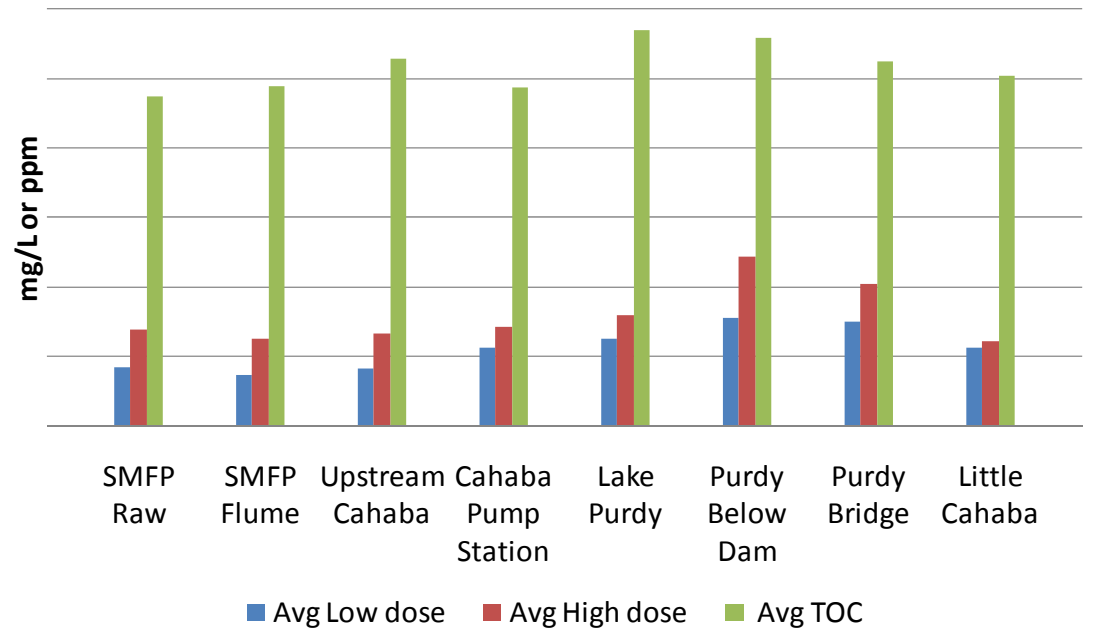

Figure 5: Integration of TOC and chlorine demand data. 


\section{Conclusion}

When evaluating the most effective ways to optimize a drinking water treatment plant it is worthwhile to encompass the raw source water into the equation. This data is very effective in illustrating the role that TOC has on the chlorine demand for a certain type of source water; generally the higher the TOC the higher the chlorine demand. Interestingly, the relationship between the two separate chlorine doses is not linear. This data is also very effective at determining which of the two raw water sources, Lake Purdy or the Cahaba River, is responsible for different blends of raw water that arrive at the treatment plant. As shown by the differences in chlorine demand between the two sources, this is something that must be carefully monitored by operators when making key treatment process decisions. This study further validates the importance that source water monitoring has on the drinking water treatment process.

\section{Future work}

Just over a year's worth of data has been collected up to this point in the project. This preliminary sampling will continue up until the summer months. By summer of 2011 solar powered circulation devices will be introduced to the Lake Purdy reservoir. These devices will promotes aeration to the reservoir and should stimulate a healthier overall water quality. The current sampling procedure will continue for approximately one year after the implementation of the solar powered mixing devices. At that time a data analysis will be performed to determine how effective these devices have been in increasing the overall water quality of the lake, specifically TOC and the resulting chlorine demand.

There is a wealth of information that can be acquired through the graphs of TOC and chlorine demand from each of the sites in this study. Further analysis of each of the sites TOC and chlorine demand values individually could possibly develop a map for future use. Turbidity data should be incorporated into this scenario as well.

A full analysis of the role that the weather conditions have played on this study would provide a vital portion of information. This is particularly useful when dealing with Lake Purdy and seasonal turnover issues.

Staff will also continue to evaluate the relationship between full scale treatment and DBPs in the distribution systems of SMFP as they pertain to the particular source waters.

\section{References}

[1] United States Environmental Protection Agency (USEPA). Proposed Stage 2 Disinfectants \& Disinfection By-products Rule. Office of Water Website, Washington DC, EPA 815-F-03-006. http://www.epa.gov/safewater.

[2] Cochran, J., Barron, P \& Nabors, A., Comprehensive Testing of Hydrogen Peroxide to Replace the Chlorine Pre-Oxidant feed at the Rapid Mix in a 
Drinking Water Filter Plant. Proc. Of the AiChE Spring Meeting and 6th Global Congress on Process Safety, San Antonio: Texas, 56a, 2010.

[3] Cochran, J., Barron, P; \& Nabors, A., Hydrogen Peroxide with Potassium Permanganate to Replace Pre-Oxidant Chlorine in Drinking Water. Proc. of the 5th Int. Conf. on Environmental Science and Technology, Houston: Texas, pp. 11, 2010.

[4] Cochran, J., Barron, P. \& Nabors, A., Comparing Multiple Oxidizers Ability to Replace a Chlorine Pre-Oxidant Addition in a Drinking Water Filter Plant. Proc. Of the AiChE Spring Meeting and 7th Global Congress on Process Safety, Chicago: Illinois, 2010.

[5] Water Research Foundation, Cost-Effective Regulatory Compliance With GAC Bio-filters, Denver: Colorado, pp. xxii, 2010.

[6] Archer, A.D. \& Singer, P.C., An Evaluation of the relationship between SUVA and NOM coagulation using the ICR database. Journal AWWA, 102:10, pp. 110-126, 2006.

[7] Krasner, S.W., Westerhoff, P., Chen, B., Rittmann, B.E., Nam, S., \& Amy, G., Impact of Wastewater Treatment Processes on Organic Carbon, Organic Nitrogen, and DBP Precursors in Effluent Organic Matter. Environmental Science \&Technology, 10:1021, 2009.

[8] Roy, A.J., Treatment alternatives for compliance with the Stage 2 D/DBPR: An economic update. Journal AWWA, 102:3, pp. 44-51, 2010.

[9] Volk, C.J. \& Lechevallier, M.W., Effects of Conventional Treatment on AOC and BDOC levels. Journal AWWA, 94:6, pp. 112-123, 2002.

[10] Nijhuas, M., The Cahaba: A River of Riches. Smithsonian, Vol. 40 No. 5, pp. 28-35, August 2009.

[11] Nabors, A. Barron, P; \& Cochran, J., Monitoring of Source Water Supplied to a Treatment Plant to Evaluate its effect on Influent Water Quality. Proc. Of the 5th Int. Conf. on Environmental Science and Technology, Houston: Texas, pp. 10, 2010.

[12] United States Geological Survey (USGS). Birmingham South Quadrangle, Alabama map, 1959, revised 1970 \& 1978.

[13] USGS. Cahaba Heights Quadrangle, Alabama map, 1959 revised 1970 \& 1978. 